\title{
Basic Measurement of Air Flow in the Working Environment
}

\author{
Peter Hrabovský ${ }^{1}$, Zuzana Kolková ${ }^{1}$, Jozef Matúšov ${ }^{1}$, Pavol Belány ${ }^{1}$ \\ ${ }^{1}$ Research Centre of University of Zilina \\ Univerzitná 8215/1, 01026 Žilina, Slovakia \\ peter.hrabovsky@uniza.sk
}

\begin{abstract}
The article deals with the climatic conditions of the indoor working environment. The building is a laboratory room designed for long-term stay of people in the space. Climatic conditions of the room are regulated by automated heating and ventilation systems based on measured values of temperature, humidity, $\mathrm{CO} 2$ concentration by means of central sensors located on the wall in the room. The use of analytical laboratory equipment produces waste heat and increases the $\mathrm{CO} 2$ concentration, which leads to more intensive air exchange in the room. Air exchange indirectly affects the thermal comfort of those working. An indirect effect is the air flow rate, which is automatically regulated based on air quality and $\mathrm{CO} 2$ concentration. Draft-sensitive people may perform poorly due to impaired thermal comfort. By eliminating adverse effects, it is possible to ensure thermal well-being and comfort for working people. By using a mobile measuring system for indoor climatic conditions of the space, it is possible to determine adverse internal influences and their elimination in the working environment. Based on the measurements, it is possible to appropriately place the laboratory instruments and equipment of the room.
\end{abstract}

Keywords: thermal energy, ambient temperature, operative temperature, humidity, air velocity, draught

\section{Introduction}

Climatic conditions of the working environment are defined by the character of work and the nature of persons. The character of the work is possible by the position of the person at work (sitting, standing, their combination), the difficulty of the work performed. The nature of a person is defined by gender (woman, man), physical and mental condition. Based on the character of work and the nature of the person, the basic comfortable climatic conditions of thermal comfort can be defined [1]. Thermal comfort can be ensured by means of built-in central heating, ventilation and cooling systems. These systems can be controlled automatically by sensors of temperature, humidity, quality and concentration of $\mathrm{CO}_{2}$ in the air or manually by thermostats and by setting associated technologies of central systems such as. Adjustment of humidity and temperature by means of air conditioning, air exchange by means of a ventilation system with the possibility of using waste heat or cold and the like. When working in laboratory areas, it is necessary to pay attention to the quality of the environment due to the safety and sensitivity of those present [2]. Many laboratory devices produce waste heat, which results in an increase in ambient temperature, a change in humidity and an increase in $\mathrm{CO}_{2}$ concentration, which has a negative effect on human health and reduces work performance. An example of a negative effect is, for example, drafts, which causes an unpleasant feeling of the area of the head and the whole spine by stiffening of the muscles or a cold [3]. These effects can be eliminated by adjusting the control system for adjusting the climatic conditions in the room, changing the layout of furniture and laboratory equipment, which is related to the position of the person with respect to the direction of air flow. It is possible to go through several negative influences in the design and planning of space, HVAC systems and control using mathematical calculations and simulations of air flow and climate change, which can show us the appropriate location of individual workplaces, orientation and position of people in space [4]. At the existing workplace, it is possible to use mobile measuring devices for temperature, humidity, air flow rate and draft. These devices analyze the measured data and on the basis of the parameters PMV and PPD, which are the assumed parameters of the percentage evaluation of dissatisfied users of the space. The aim is to ensure a feeling of satisfaction with the environment and also to increase work performance and a feeling of comfort. 


\section{Measurement system}

The method of predicting thermal comfort and the feeling of thermal dissatisfaction in people exposed to the environment loaded with heat, allows the analytical determination and interpretation of thermal comfort using the evaluation criteria PMV and PPD according to the set climatic conditions of the room. This method of evaluation and prediction of thermal comfort in buildings is suitable for designing new environments or when assessing existing environments.

The measurement method was used with the Dantec Comfort Sense measuring system. The measuring system records changes in temperature, humidity, flow rate. Based on the measured values, we obtain the calculation according to International Standards EN 13182, ISO 7726, 7730, ASHRAE standard 113 and ASHRAE standard 55. The basic evaluation criteria for ensuring the thermal comfort of PPD and PMV inform us about the quality of the environment in terms of temperature and air exchange at the percentage of employees.
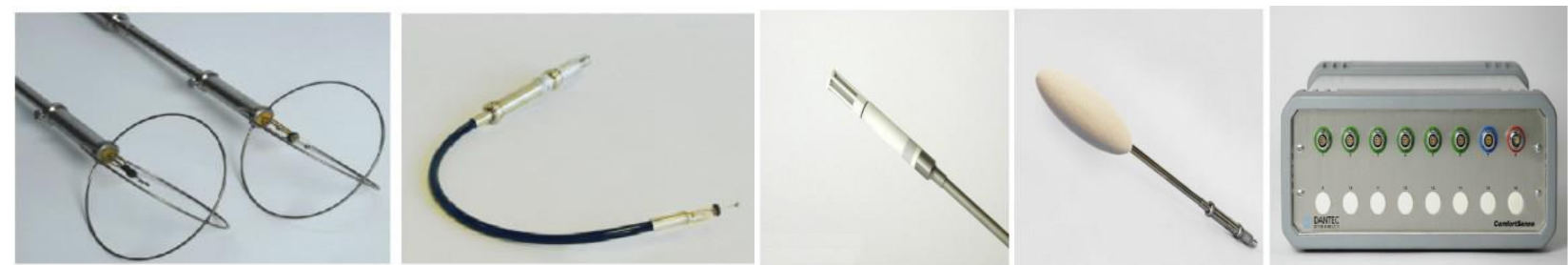

Fig. 1: Measurement probes of temperature, velocity, humidity, operative temperature and main frame.

The manikin version of the draft probe is very compact, with a flexible cable connection to the probe tip, making it suitable for building into a manikin for passenger comfort applications. Velocity range is 0.05 to $5 \mathrm{~m} / \mathrm{s}$, indicates up to $10 \mathrm{~m} / \mathrm{s}$ and temperature is -20 to $80{ }^{\circ} \mathrm{C}$ for both types. Robust velocity and temperature probe has velocity range 0.1 to $30 \mathrm{~m} / \mathrm{s}$. Humidity range is $0-100 \%$. Dantec has also operative temperature probe. The sensor element simulates a standing person when it is vertical, a sitting person when tilted $30{ }^{\circ} \mathrm{C}$ from vertical and a reclining person when in the horizontal position. Temperature range is $0-45^{\circ} \mathrm{C}$

\section{Result}

The object of air flow measurement is the laboratory room in which the chemical solution analyzer is located. During the operation of the device, there is an increased production of waste heat, which is the cause of changes in the climatic conditions of the comfort and thermal comfort of those present. The measurement took place in the realization part of the room according to the Figure 2 marked by red circles. The basic measuring points were defined by an even distribution according to the assumed movement and retention of the person in the space. 

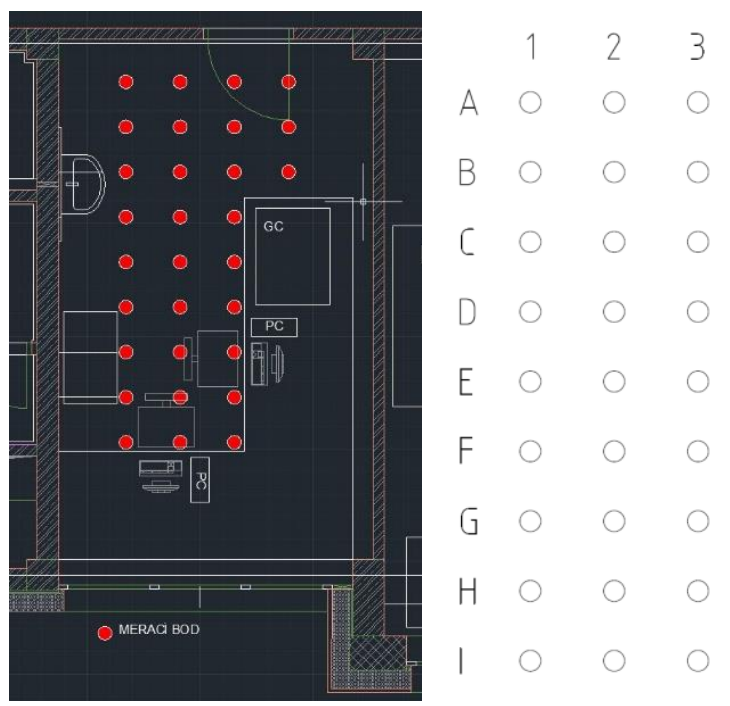

Fig. 2: Checkerboard layout of measuring points in the room.
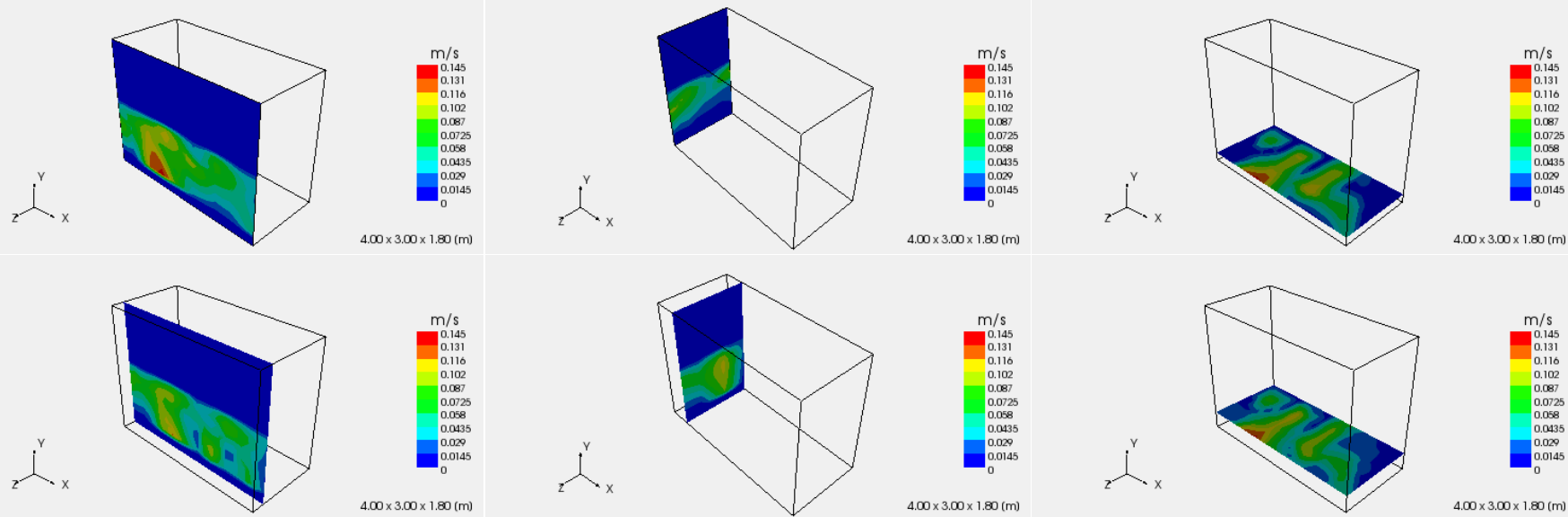

$4.00 \times 3.00 \times 1.80(\mathrm{~m})$

$4.00 \times 3.00 \times 1.80(\mathrm{~m})$

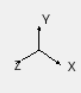

$4.00 \times 3.00 \times 1.80(\mathrm{~m})$
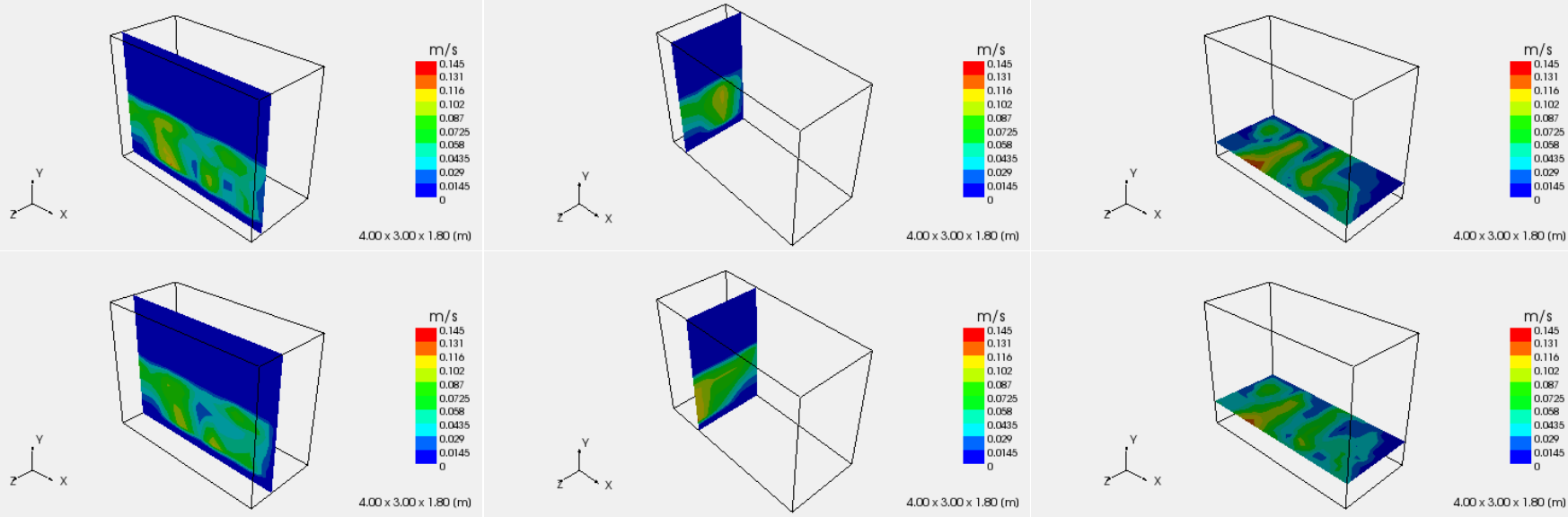

$4.00 \times 3.00 \times 1.80(\mathrm{~m})$
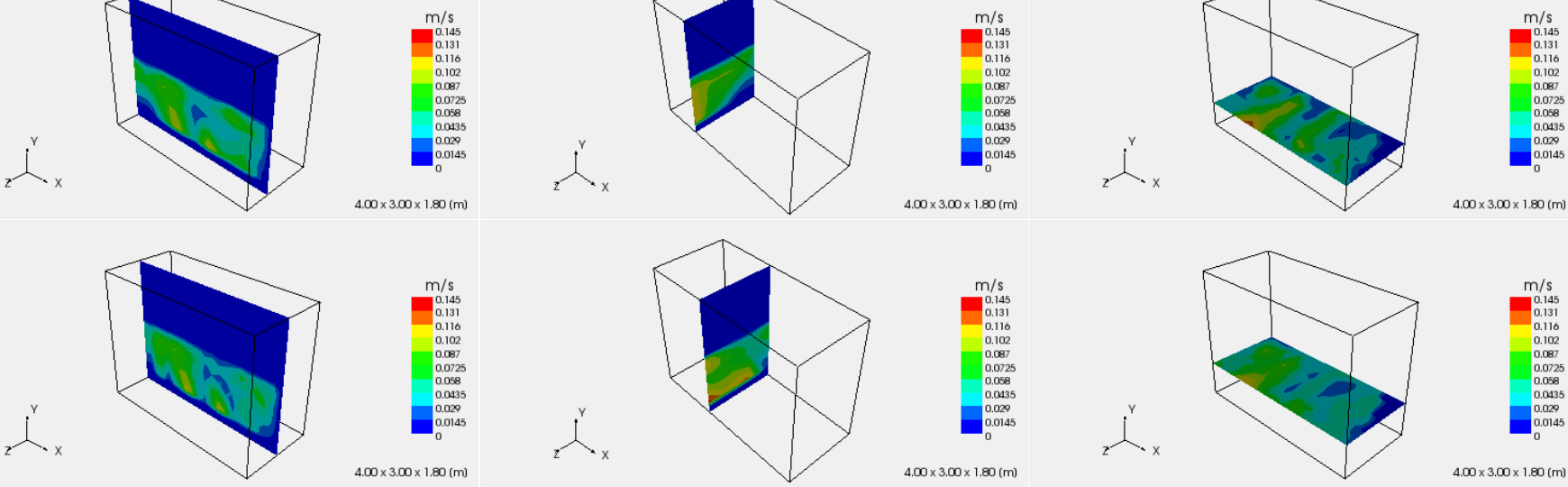

$4.00 \times 3.00 \times 1.80(\mathrm{~m})$
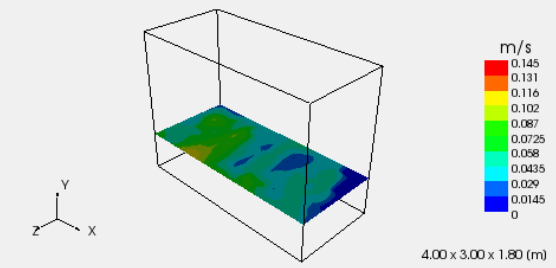

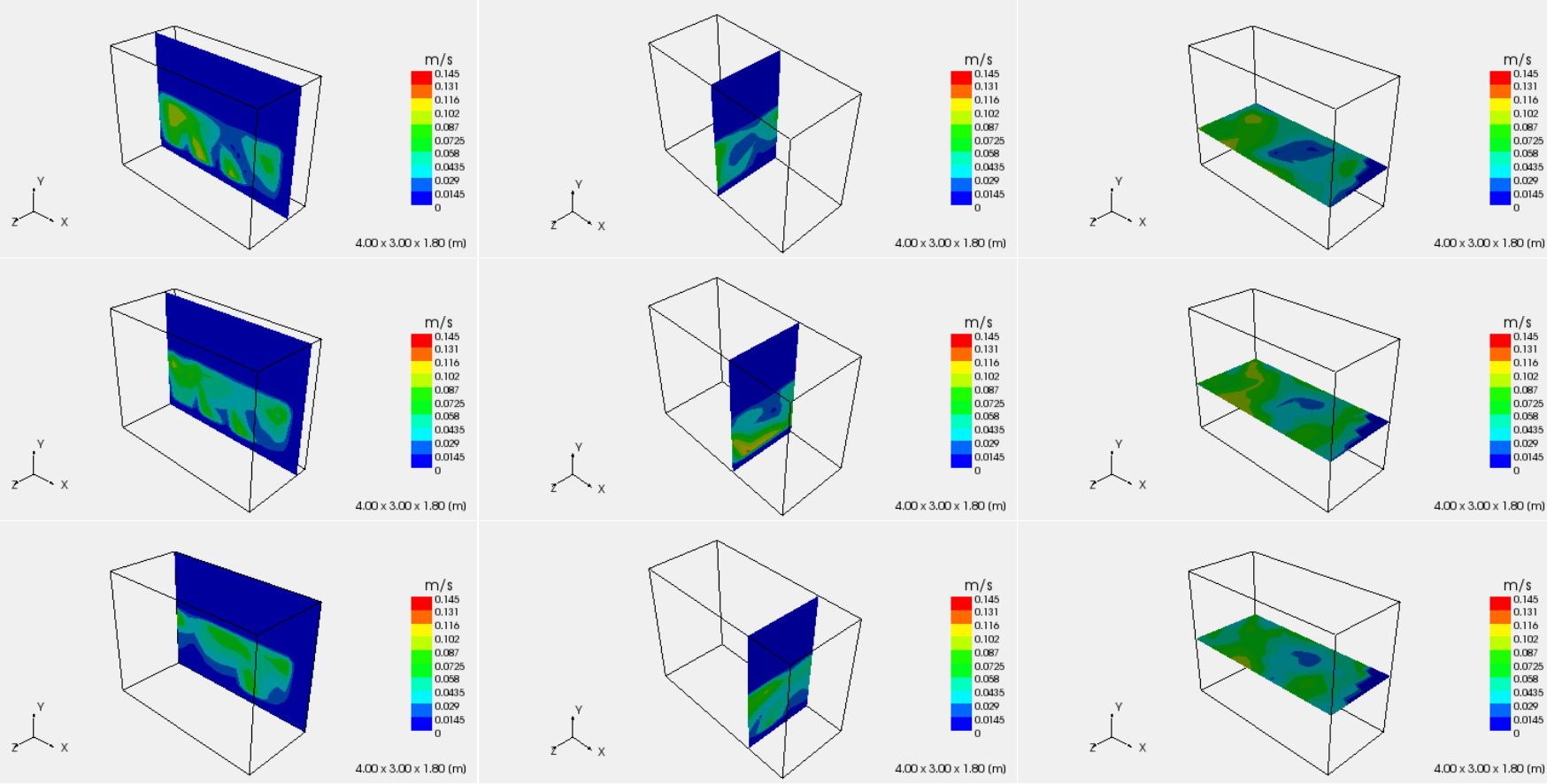

$4.00 \times 3.00 \times 1.80 \mathrm{~cm}$
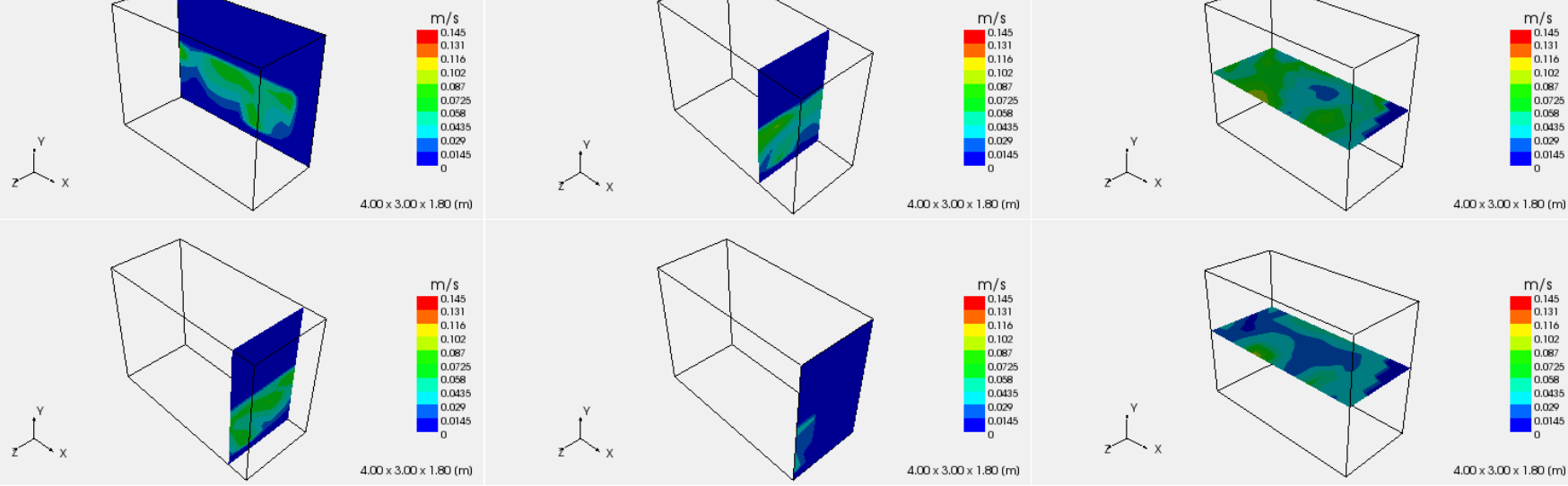

Fig. 3: Measured air velocity output in the spatial planes.

The expected output of the measurement is the result of spatial planes Figure 3, which show us the individual places or. Positions with a defined air velocity. From the individual spatial levels and their mutual combination, it is possible to judge the negative impact of the presence of people in individual positions in space, but also positions with favorable conditions for the person to remain while maintaining comfort and thermal comfort. 


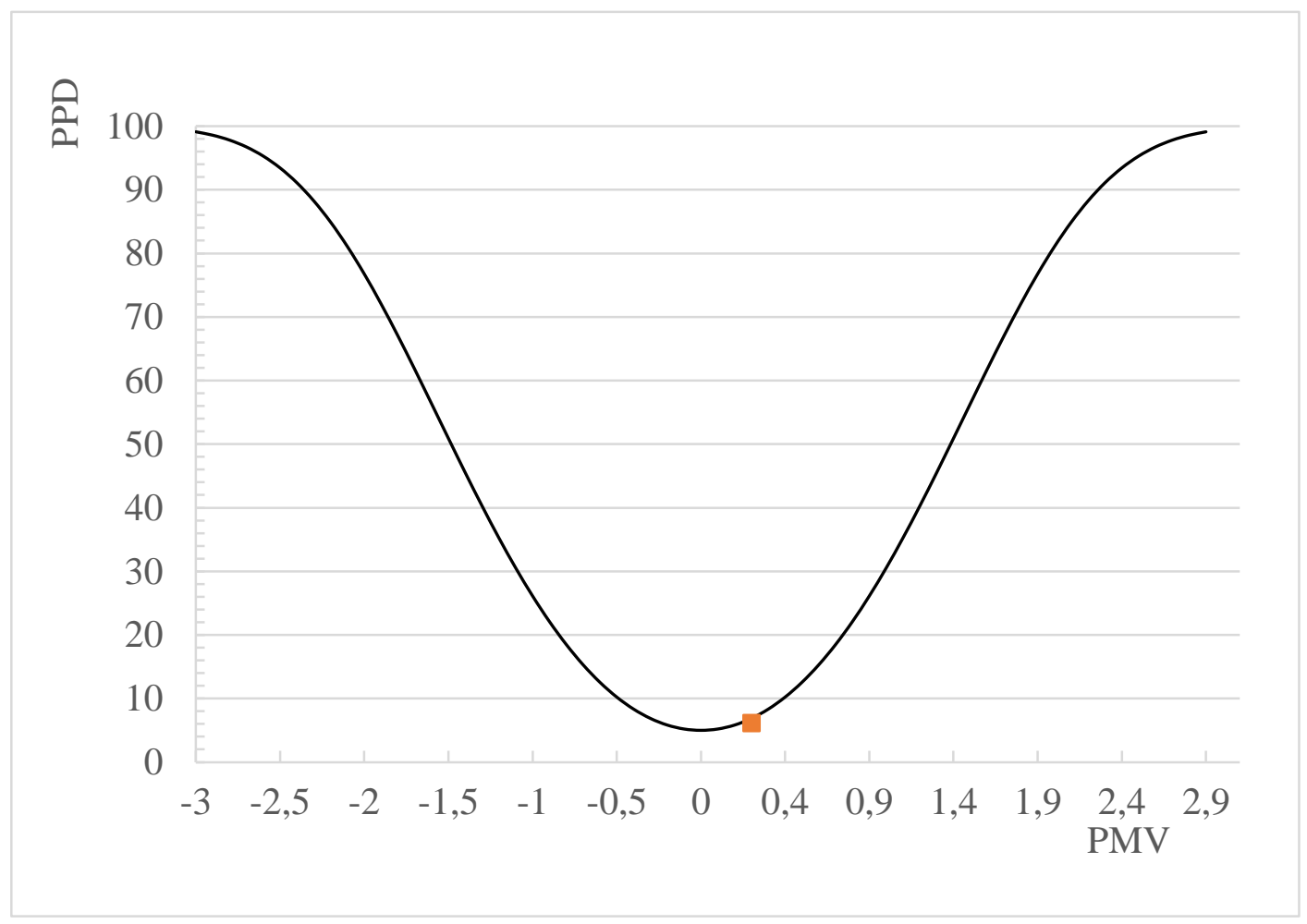

Fig. 4: Index PDD a PMV.

PMV predicted mean vote

PPD predicted percentage dissatisfied \%

Figure 4 shows us the overall result of the evaluation of the comfort and thermal comfort of the laboratory room. The basic climatic conditions of the room were stabilized at the following values: room air temperature $24{ }^{\circ} \mathrm{C}$, air humidity $30 \%$, air flow speed $8 \mathrm{~m} / \mathrm{s}$. The result of the evaluation is given by the PMV parameter, which is on the border of a neutral and moderately warm environment according to the above-mentioned standards.

\section{Conclusion}

Creating a project and designing the room and layout of the facilities seems to be a simple task, but after considering all the influences that affect the work environment and the work performance of people, it has proved to be an essential part. Therefore, it is necessary to take into account not only the equipment but also the climatic conditions of the room to ensure the comfort and thermal well-being of those present. This article describes the state and influence of air flow in space, at steady, constant values of temperature, humidity and air flow rate. It is the basis for creating a mathematical model and simulation under different climatic conditions, room equipment and the nature of the work. By comparing the achieved results with the prepared mathematical model and simulation, it is possible to create a universal model for the design and layout of equipment for new or existing rooms in buildings.

\section{Acknowledgements}

"This publication was realized with support of Operational Program Integrated Infrastructure 2014 - 2020 of the project: Innovative Solutions for Propulsion, Power and Safety Components of Transport Vehicles, code ITMS 313011V334, cofinanced by the European Regional Development Fund" and this work was supported by Grant System of University of Zilina No. 8021. 1/2020. 


\section{References}

[1] K. Parsons, Human Thermal Environmentals, CRC Press, 635 p. (2014)

[2] S. Carlucci, Thermal Comfort Assessment of Buildings, Springer-Verlag Mailand, (2013)

[3] STN 73 0540-3:2012: Thermal protection of buildings.Thermal performance of buildings and components.Part 3: Properties of environments and building products

[4] STN EN ISO 7730:2006: Ergonomics of the thermal environment - Analytical determination and interpretation of thermal comfort using calculation of the PMV and PPD indices and local thermal comfort criteria (ISO 7730:2005) 